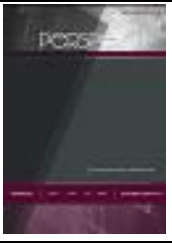

\title{
Analisis Kontribusi Sektor Perhubungan terhadap Pendapatan Asli Daerah di Kabupaten Aceh Tengah
}

\section{Analysis of the Contribution of the Transportation Sector to Local Revenue in Central Aceh District}

\author{
Ravika Ramadayani1)*, Irwan Nasution'1) \& Armansyah Matondang ${ }^{2)}$ \\ 1) Program Studi Ilmu Pemerintahan, Fakultas Ilmu Sosial dan Ilmu Politik \\ Universitas Medan Area, Indonesia \\ 2) Program Studi Ilmu Komunikasi, Fakultas Ilmu Sosial dan Ilmu Politik \\ Universitas Medan Area, Indonesia
}

Diterima: Mei 2019; Disetujui: Juni 2019; Dipublish: Juni 2019

\begin{abstract}
Abstrak
Fungsi otonomi daerah yaitu untuk mengatur dan mengurus urusan pemerintahan di daerah, pelaksanaan otonomi daerah membawa pengaruh penting untuk setiap daerah agar lebih kreatif dalam memanfaatkan sumber-sumber ekonomi yang ada di daerah demi keberhasilan pelaksanaan pembangunan di daerah. Dalam hal ini Pemerintahan Kabupaten Aceh Tengah berupaya menggali potensi dana yang dapat meningkatkan Pendapatan Asli Daerah, salah satunya yaitu dari sektor Perhubungan. Permasalahan yang dirumuskan adalah "Bagaimana perkembangan kontribusi Sektor Perhubungan terhadap Penerimaan Asli Daerah (PAD) Kabupaten Aceh Tengah Kota Takengon pada tahun 2016-2017. Tujuan penulisan ini adalah untuk mengetahui besarnya perkembangan kontribusi dari setiap bidang dan Unit Pelaksanaan Teknis (UPT) pada Dinas Perhubungan terhadap Pendapatan Asli Daerah di Kabupaten Aceh Tengah. Dalam penelitian ini penulis menggunakan metode deskriptif dengan analisis data kualitatif dimana peniliti adalah instrument kunci, teknik pengumpulan data dilakukan dengan cara triagulasi (gabungan). Berdasarkan pembahasan maka dapat disimpulkan bahwa, penerimaan dari sektor perhubungan yang dikumpulkan dari setiap Bidang dan Unit Pelaksana Teknis (UPT) yang berada di Dinas Perhubungan dalam jangka waktu 2 tahun ini cenderung mengalami penurunan dari tahun sebelumnya, yang mengalami peningkatan hanya dari hasil retribusi pelayanan parkir di tepi jalan umum dan retribusi pemakaian kekayaan daerah.

Kata Kunci: Perhubungan, Pendapatan, Daerah
\end{abstract}

\begin{abstract}
The function of regional autonomy is to regulate and manage government affairs in the region, the implementation of regional autonomy has an important influence for each region to be more creative in utilizing existing economic resources in the region for the successful implementation of development in the region. In this case the Central Aceh District Government seeks to explore the potential of funds that can increase Regional Original Revenue, one of which is from the Transportation sector. The problem that was formulated was "How is the development of the contribution of the Transportation Sector to the Original Regional Revenue (PAD) of Central Aceh District of Takengon City in 2016-2017. The purpose of this paper is to find out the magnitude of the development of contributions from each field and the Technical Implementation Unit (UPT) at the Department of Transportation to Regional Original Revenue in Central Aceh District. In this study the author uses descriptive methods with qualitative data analysis where researchers are key instruments, data collection techniques are done by triagulation (combined). Based on the discussion, it can be concluded that, revenues from the transportation sector collected from each Field and Technical Implementation Unit (UPT) in the Transportation Agency within 2 years tend to decline from the previous year, which only increased from the results of parking service fees on the edge of public roads and regional wealth usage levies.
\end{abstract}

Keywords: Transportation, Income, Area

How to Cite: Ramadayani, R. Nasution, I. Matondang, A. (2018). Analisis Kontribusi Sektor Perhubungan terhadap Pendapatan Asli Daerah di Kabupaten Aceh Tengah, PERSPEKTIF, 7 (2): 50-54

${ }^{*}$ Corresponding author:

ISSN 2085-0328 (Print)

E-mail:Ramadayani97@gmail.com 


\section{PENDAHULUAN}

Pemerintah daerah dengan otonom adalah proses peralihan dari sistem dekonsentrasi ke sistem desentralisasi. Otonomi adalah penyerahan urusan pemerintah pusat ke pemerintah daerah yang bersifat operasional dalam rangka sistem birokrasi pemerintahan. Tujuan otonomi adalah mencapai efesiensi dan efektivitas dalam pelayanan kepada masyarakat. Tujuan yang hendak dicapai dalam penyerahan urusan ini adalah antara lain, menumbuhkembangkan daerah, dalam berbagai bidang, meningkatkan pelayanan kepada masyarakat, menumbuhkan kemandirian daerah, dan meningkatkan daya saing daerah dalam proses pertumbuhan. (Widjaja, 2002).

Sehubungan dengan hal itu sebenarnya pemerintah sudah mengatur masalah keuangan yang menjadi tugas pemerintah pusat di daerah menjadi beban APBN. Dana ini diperuntukkan dalam rangka dekonsentrasi sementara urusan-urusan yang menjadi tugas daerah otonom dalam rangka desentralisasi dilimpahkan dalam APBD daerah yang bersangkutan (Rosmaniar, 2012). Dalam menggulirkan program otonomi diberikan kebebasan bagi daerah kabupaten menyusun dan mengatur rumah tangganya sendiri, akan tetapi dilaksanakan dengan loyalitas serta disiplin yang tinggi. Tugas-tugas yang diemban tidak terlepas dari resiko dan tantangan tinggi (Sitompul \& Lubis, 2013).

Kabupaten Aceh Tengah dalam kaitannya dengan pertumbuhan daerah, guna mendukung perekonomian di Kabupaten Aceh Tengah salah satunya melalui upaya pembangunan sektor perhubungan. Pembangunan sektor perhubungan di Aceh Tengah didukung oleh beberapa hal, antar alain : 1) Letak geografis Kabupaten Aceh Tengah khususnya Kota Takengon yang strategis; 2) sebagai salah satu kota transit yang dilalui oleh jalan lintas Sumatera dan lintas Aceh; 3) Kabupaten Aceh Tengah memiliki aktivitas yang tinggi sangat membutuhkan sarana perhubungan yang baik untuk mempermudah aktifitas dari warganya.

Untuk memberikan pelayanan yang baik kepada masyarakat, pemerintah Kabupaten Aceh Tengah membentuk dinas Perhubungan sebagai unsur pelaksana dalam hal mengatur perhubungan di Aceh Tengah. Untuk mewujudkan pelayanan yang baik di Kota Takengon Dinas Perhubungan mempunyai fungsi: 1). Melakukan penyusunan penetapan jaringan transportasi jalan kota; 2) Melaksanakan perencanaan dan penetapan lokasi terminal Bus; 3) Pelaksanaan penyelenggarakan perpakiran kenderaan bermotor serta penetapan izin pembangunan dan pengoperasian tempat parkir serta penetapan tarif parkir. 4) Melaksanakan uji berkala kenderaan bermotor melalui penyediaan fasilitas pengujian kenderaan bermotor dan adminitrasi kenderaan bermotor. 5) Penetapan jaringan trayek dan komposisi angkutan ekonomi dan non ekonomi serta memberi izin pengoperasian angkutan wilayah kota. 6). Membentuk Unit Pelaksana Teknis (UPT) sebagai pembantu dinas dalam menjalankan tugas dan fungsinya, adapun UPT yang ada di Dinas Perhubungan: a. UPT Perparkiran; b. UPT Pengujian Kenderaan Bermotor; c. UPT Terminal.

$$
\text { Dalam usaha meningkatkan }
$$

perekonomian daerah, maka sektor perhubungan merupakan salah satu sumber penerimaan bagi daerah yang dapat meningkatkan Pendapatan Asli Daerah (PAD) di Aceh Tengah. Untuk itu dengan diberikannya hak otonomi kepada daerah, maka baik daerah propinsi maupun kabupaten/kota diharapkan mampu untuk terus menggali potensi daerahnya masingmasing sesuai dengan kewenangannya sehingga pada akhirnya dapat meningkatkan sumber-sumber penerimaan bagi pendapatan daerah.

Berdasarkan Undang-undang No. 25 tahun 1999 yang direvisi menjadi undangundang No. 33 Tahun 2004 tentang Perimbangan Keuangan antara Pemerintah Pusat dan Daerah, menyatakan bahwa sumber penerimaan daerah, sumber-sumber pendapatan asli daerah (PAD) terdiri dari: 1) Hasil pajak daerah; 2) Hasil retribusi daerah; 3) Hasil perusahaan milik daerah dan hasil pengelolaan kekayaan daerah lainnya yang dipisahkan; 4) Lain-lain PAD yang sah

Pengertian Pendapatan Asli Daerah (PAD) menurut Undang-undang No. 22 Tahun 1999, tentang Otonomi Daerah adalah penerimaan yang diperoleh daerah dari sumber-sumber dalam wilayahnya sendiri 
yang dipungut berdasarkan peraturan daerah sesuai peraturan perundangan yang berlaku.

Dalam penyelenggaraan Pemerintahan menjalankan hak dan wewenang untuk mengartur daerah, pemerintah daerah sering mengalami kesulitan dan kendala dimana Pendapatan Asli Daerah (PAD) belum mampu membiayai penyelengaraan pemerintahaan di daerah atau belum seperti yang diharapkan. Retribusi dari sektor perhubungan merupakan salah satu sumber pendapatan daerah yang memiliki arti penting di samping sumbersumber pendapatan daerah lainnya, untuk itu perlu dikembangkan lagi pendapatannya agar menjadi jauh lebih baik.

\section{METODE PENELITIAN}

Dalam penelitian ini, penulis menggunakan penelitian kualitatif. Menurut (Sugiyono, 2011) bahwa: Metode penelitian kualitatif adalah metode yang berdasarkan pada filsafat postpositivisme, sedangkan untuk meneliti objek alamiah, dimana peneliti adalah sebagai instrument kunci, teknik pengumpulan data dilakukan dengan cara triangulasi (gabungan). Analisis data bersifat induktif atau kualitatif, dan hasil penelitian lebih menekankan makna daripada generalisasi.

Lokasi penelitian ini dilaksanakan di kantor Dinas Perhubungan di jl. Pasar paya ilang kp. Tan Saril kec. Bebesen. Penelitian ini dilaksanakan dengan mengumpulkan data melalui observasi, dokumentasi, dan wawancara kepada Sekretaris Dinas Perhubungan, Bendahara Dinas Perhubungan dan Ketua Organda Kabupaten Aceh Tengah.Waktu penelitian ini dilaksanakan pada bulan April.

Untuk memperoleh data dari lapangan, peneliti menggunakan beberapa metode pengumpulan data sesuai dengan jenis penelitian, adapun metode pengumpulan data sebagai berikut: a) Kepustakaan, Studi kepustakaan adalah segala usaha yang dilakukan untuk menghimpun informasi yang relevan dengan topik/masalah yang akan/sedang diteliti. 2) Observasi adalah pengamatan dan pencatatan yang sistematis terhadap gejala-gejala yang diteliti. 3) Wawancara, adalah proses memperoleh keterangan untuk tujuan penelitian dengan cara tanya jawab sambil bertatap muka antar si penanya dengan si penjawab atau responden dengan menggunakan alat yang dinamakan interview guide (panduan wawancara). 4) Dokumentasi adalah mencari data mengenai hal-hal yang berhubungan dengan penelitian berupa catatan, transkip, buku, surat kabar, majalah, notulen, rapat, agenda dan sebagainya.

Analisis data di artikan sebagai upaya mengelola data menjadi informasi, sehingga karakteristik atau sifat-sifat data tersebut dapat dengan mudah di pahami dan bermanfaat untuk menjawab masalahmasalah yang berkaitan dengan kegiatan penelitian. Dengan demikian, teknik analisis data dapat di artikan sebagai pelaksaan analisis terhadap data, dengan tujuan mengelola data tersebut menjadi informan, sehingga karakteristik atau sifat-sifat datanya dapat dengan mudah di pahami dan bermanfaat untuk menjawab masalahmasalah yang berkaitan dengan penelitian, baik berkaitan dengan dekripsi data maupun untuk membuat induksi, atau menarik kesimpulan tentang karakteristik populasi (parameter) berdasarkan data yang di peroleh dari sampel (statistik).

Metode analisis data yang di gunakan dalam penelitian ini adalah model analisis interaktif. Model interaktif ini di lakukan dengan tiga langkah data kualitatif, yaitu reduksi data, sajian data, dan penarikan kesimpulan dan verifikasi.

\section{HASIL DAN PEMBAHASAN}

Pengumpulan data penelitian yaitu dengan mengumpulkan berbagai data yang diperlukan dalam penelitian langkah ini dilakukan sesuai dengan teknik pengumpulan data penelitian yang dilakukan. Teknik yang dilakukan adalah wawancara, pengamatan. Klasifikasi data penelitian meliputi proses penelitian, pemusatan perhatian pada penyederhanaan data kasar dari catatan tertulislapangan penelitian, membuat ringkasan, penggolongan jawaban dan kualifikasi jawaban/responden/informanpenelitian kembali catatan yang telah diperoleh setelah mengumpulkan data. Analisis data meliputi meliputi penyusunan penyajian kategori jawaban informan disertai dengan temuan awal terhadap berbagai temuan data di lapangan sebagai proses awal dalam 
pengolahan data. Langkah terkahir adalah pembahasan yaitu pembahasan yang berdasarkan pada rujukan berbagai teori yang digunakan dimana di dalamnya ditentukan suatu kepastian mengenai aspek teori dan kesesuaian/ketidaksesuaian dengan fakta hasil penelitian di lapangan dimana peneliti juga membuat suatu analisis serta interpretasi/membuat tafsiran atas tampilan data secara deskriptif sesuai dengan permasalahan penelitian.Berdasarkan tujuan dari penelitian maka untuk mengetahui perkembangan dari kontribusi sektor perhubungan terhadap Penerimaan Asli Daerah (PAD) kabupaten Aceh Tengah. Sektor perhubungan yang berada pada sebuah dinas yaitu dinas perhubungan memiliki beberapa Unit Pelaksana Teknis (UPT), UPT yang ada meliputi UPT Perparkiran, Pengujian Kendaraan Bermotor, Terminal. Dari setiap UPT yang berada di bawah naungan dinas perhubungan ini aset-aset daerah dikelola dan melakukan penarikan dana dari masyarakat baik secara langsung dan tidak langsung. Setiap UPT yang ada di Dinas Perhubungan memberikan sumbangan terhadap Penerimaan daerah Kabupaten Aceh Tengah. Pada tahun 2017 terdapat peningkatan retribusi pelayanan parkir tepi jalan umum menjadi Rp.143.215.000 dari tahun sebelumnya, retribusi pengujian kendaraan bermotor mengalami penurunan menjadi Rp.70.395.000, retribusi jasa usaha juga mengalami penurunan menjadi Rp.76.585.000, retribusi pemakaian kekayaan daerah mengalami peningkatan menjadi Rp.9.250.000, retribusi terminal cukup jauh mengalami penurunan menjadi Rp.28.655.000, dan retribusi perizinan tertentu juga mengalami penurunan menjadi Rp.3.800.000. Jika dijumlahkan keseluruhan dari hasil tersebut pada tahun 2017 mengalami peningkatan menjadi Rp.519.550.008 dari tahun sebelumnya yangdapat diberikan ke Pendapatan Asli Daerah.Target penerimaan daerah disusun oleh Pemerintah Kabupaten/Kota pada setiap awal tahun anggaran yang berlaku. Penyusunan target Penerimaan Daerah Kota Kabupaten Aceh Tengah disusun oleh instansi yang ada di lingkungan pemerintah khususnya sektor perhubungan yang dibuat oleh Dinas Perhubungan.
Dari tabel 4.2 dapat dilihat bahwa pada tahun 2016 retribusi pelayanan parkir di tepi jalan umum belum mencapai target sedangkan pada tahun 2017 sudah melebihi target, retribusi pengujian kendaraan bermotor pada tahun 2016 juga belum mencapai target sama seperti tahun 2017 juga belum mencapai target, retribusi jasa usaha pada tahun 2016 sudah mencapai target sedangkan pada tahun 2017 tidak mencapai target, retribusi pemakaian kekayaan daerah pada tahun 2016 belum mencapai target sama hal nya seperti tahun 2017 juga belum mencapai target, retribusi terminal pada tahun 2016 belum mencapai target sedangkan 2017 juga sama belum mencapai target, dan retribusi perizinan tertentu pada tahun 2016 juga belum menjapai target sedangkan pada tahun 2017 juga belum mencapai target yang sudah direalisasikan. Dapat disimpulkan bahwa pada tahun 2016 dan 2017 belum mencapai target yang sudah direalisasikan.

\section{SIMPULAN}

Penerimaan dari sektor perhubungan yang dikumpulkan dari setiap Bidang dan Unit Pelaksana Teknis (UPT) yang berada di Dinas Perhubungan mengalami penurunan dari tahun sebelum nya retribusi pengujian kendaraan bermotor tahun 2016 Rp.80.390.000 turun menjadi Rp.77.395.000 pada tahun 2017, retribusi jasa usaha tahun 2016 Rp.94.400.000 turun menjadi Rp.76.585.000 pada tahun 2017, retribusi terminal pada tahun 2016 Rp.152.890.000 turun menjadi Rp.28.655.000 pada tahun 2017, dan retribusi perizinan tertentu pada tahun 2016 Rp.10.500.000 turun menjadi Rp.3.800.000, akan tetapi retribusi pelayanan parkir di tepi jalan umum mengalami peningkatan lebih dari $100 \%$ pada tahun 2016 Rp.143.215.000 meningkat menjadi Rp.323.865.008 pada tahun 2017 dan retribusi pemakaian kekayaan daerah juga mengalami peningkatan pada tahun 2016 Rp.3.000.000 meningkat menjadi Rp.9.250.000.

Potensi yang saat ini dilakukan Dinas Perhubungan untuk meningkatkan pendapatan asli daerah yaitu salah satunya dengan menetapkan target retribusi pertahun pendapatan yang harus tercapai. Dan juga sedang menyiapkan perda-perda baru agar tidak salah dalam mengutip retribusi. 
Ravika Ramadayani, Irwan Nasution \& Armansyah Matondang, Analisis Kontribusi Sektor

Perkembangan retribusi pada tahun 20162017 belum mengalami peningkatan yang cukup signifikan, bahkan lebih banyak mengalami penurunan dari tahun sebelumnya yang mengalami peningkatan yang signifikan hanya dari retribusi parkir yang meningkat dua kali lipat dari tahun sebelumnya.

\section{DAFTAR PUSTAKA}

Adisamsmita, R. (2014). Pembiayaan Pembangunan Daerah. Yogyakarta: Graha Ilmu

Arikunto, S. (1993). Prosedur Pnelitian Suatu Pendekatan Praktek. Jakarta: Rineka Cipta

Deddy, S.B. (2002). Otonomi Penyelenggara Pemerintahan Daerah. Yogyakarta: Gramedia Pustaka Utama.

Elmi, B. 2002. Keuangan Pemerintah Daerah Otonom di Indonesia. Jakarta: Universitas Indonesia.

Harry K, (2011). Analisis Kontribusi Sektor Perhubungan Terhadap Penerimaan Asli Daerah (PAD) Kota Bandar Lampung tahun 2005-2009. Universitas Bandar Lampung.

Ibrahim, M. (2007). Mujahid Dataran Tinggi Gayo. Takengon: Yayasan Maqmam Mahmuda.

Nazir. 1988. Metode Penelitian. Jakarta: Ghalia Indonesia

Qanun Kabupaten Aceh Tengah Tahun 2010 dan Peraturan Bupati Aceh Tengah tentang Pelaksanaan Qanun Kabupaten Aceh Tengah Tahun 2010
Riwu K.J. (1991). Prospek Otonomi Daerah di Negara Republik Indonesia. Identifikasi Beberapa Faktor yang mempengaruhi Penyelenggaraannya. Jakarta: Rajawali.

Rosmaniar, P, (2012), Analisis Efektivitas Dan Efisiensi Penerimaan Pendapatan Asli Daerah (Studi pada di Kabupaten Aceh Tenggara), Jurnal Administrasi Publik, 1 (1): $1-2$

Sitompul, M dan Lubis, A.A. (2013), Analisis Sumber-sumber Pendapatan Asli Daerah sebagai Modal Pembangunan, Jurnal Ilmu Pemerintahan dan Sosial Politik, 1 (1): 1-10.

Sugiyono, (2006). Metode Penelitian Administrasi. Bandung: Alfabeta

Suparmoko, M. (1986). Keuangan Negara Dalam Teori Dan Praktik. Yogyakarta: BPFEYogyakarta.

Undang - undang Republik Indonesia No. 22 Tahun 1999 tentang Pemerintahan Daerah

Undang - undang Republik Indonesia No. 33 Tahun 2004 Tentang Perimbangan Keuangan Antara Pemerintah Pusat dan Daerah. Departemen Dalam Negeri RI.

Undang - undang Republik Indonesia No. 34 Tahun 2000 tentang pajak daerah dan retribusi daerah.

Usman, H. (2011). Metodologi Penelitian Sosial. Jakarta: Bumi Akasara.

Widjaja, H.A.W. (2002). Otonomi Daerah Dan Derah Otonom. Jakarta: Rajagrafindo Persada. 